Provided for non-commercial research and education use. Not for reproduction, distribution or commercial use.

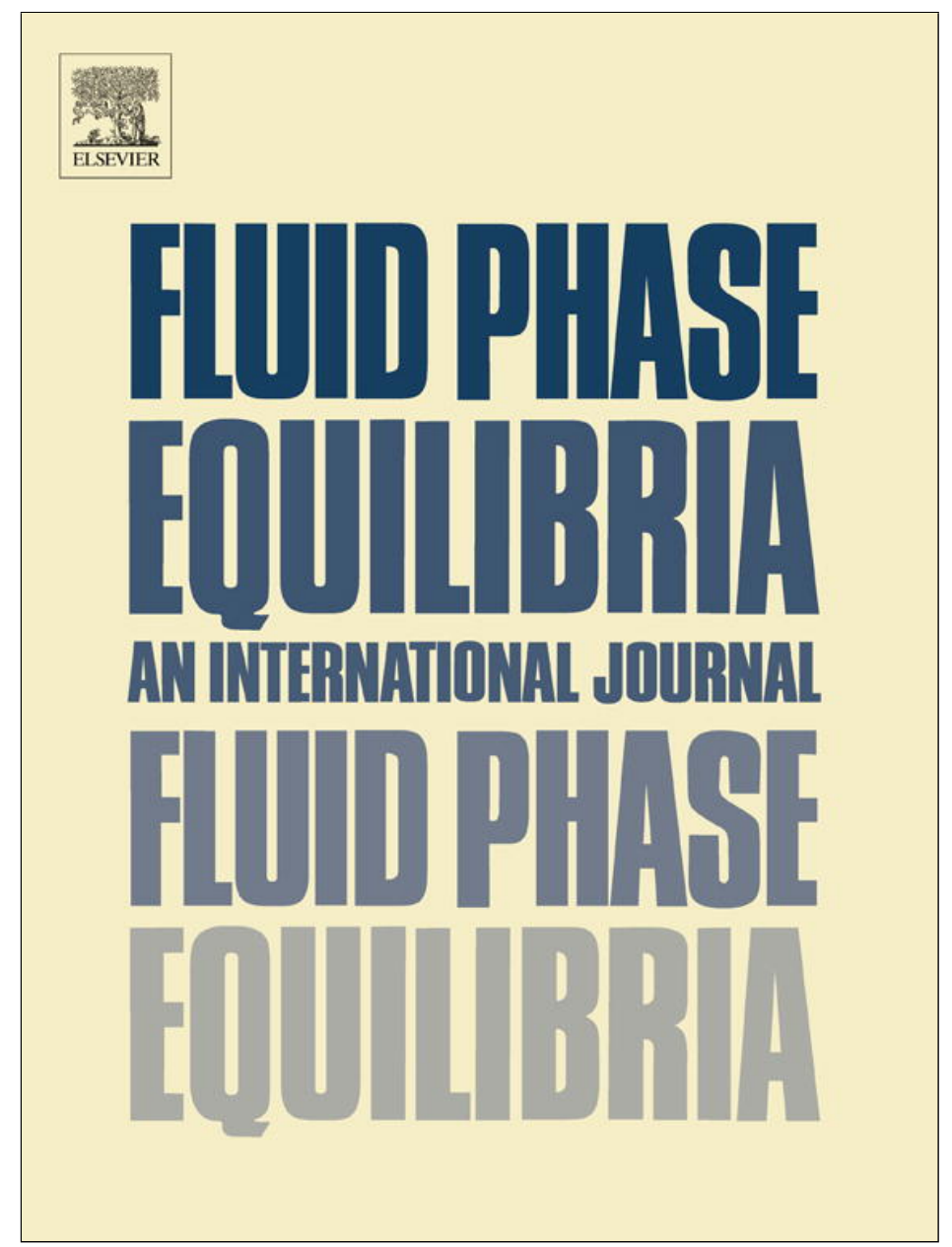

(This is a sample cover image for this issue. The actual cover is not yet available at this time.)

This article appeared in a journal published by Elsevier. The attached copy is furnished to the author for internal non-commercial research and education use, including for instruction at the authors institution and sharing with colleagues.

Other uses, including reproduction and distribution, or selling or licensing copies, or posting to personal, institutional or third party websites are prohibited.

In most cases authors are permitted to post their version of the article (e.g. in Word or Tex form) to their personal website or institutional repository. Authors requiring further information regarding Elsevier's archiving and manuscript policies are encouraged to visit:

http://www.elsevier.com/copyright 


\title{
Solubility of azadirachtin and several triterpenoid compounds extracted from neem seed kernel in supercritical $\mathrm{CO}_{2}$
}

\author{
S. Ismadji ${ }^{\text {a, }}$, A. Kurniawan ${ }^{\text {a }}$, Y.H. Ju ${ }^{\text {b }}$, F.E. Soetaredjo ${ }^{\text {a }}$, A. Ayucitra ${ }^{\text {a }}$, L.K. Ong ${ }^{\text {a }}$ \\ a Department of Chemical Engineering, Widya Mandala Surabaya Catholic University, Kalijudan 37, Surabaya 60114, Indonesia \\ ${ }^{\mathrm{b}}$ Department of Chemical Engineering, National Taiwan University of Science and Technology, 43, sec. 4, Keelung Rd., Taipei 106, Taiwan
}

\section{A R T I C L E I N F O}

\section{Article history:}

Received 9 July 2012

Received in revised form 27 August 2012

Accepted 29 August 2012

Available online 5 September 2012

\section{Keywords:}

Neem seed kernel

Azadirachtin

Triterpenoids

Solubility

Density-based model

\begin{abstract}
A B S T R A C T
The extraction of oil and several triterpenoid compounds (azadirachtin, nimbin, and salannin) from need seed kernel by supercritical $\mathrm{CO}_{2}\left(\mathrm{SC}-\mathrm{CO}_{2}\right)$ was demonstrated in this work. The experiments were performed with variation of pressures from $10 \mathrm{MPa}$ to $35 \mathrm{MPa}$ and temperatures $(313.15 \mathrm{~K}, 323.15 \mathrm{~K}$, and $333.15 \mathrm{~K}$ ) for $4 \mathrm{~h}$ with $\mathrm{CO}_{2}$ flow rate of $5 \mathrm{~mL} / \mathrm{min}$ (measured at $6.8 \mathrm{MPa}, 303.15 \mathrm{~K}$ ). The amounts of neem oil, azadirachtin, nimbin, and salannin extracted were increased with increasing pressure and temperature. The solubility of neem oil and triterpenoids studied was presented as a function of temperature and solvating power of $\mathrm{CO}_{2}$ in $3 \mathrm{D}$ mesh plots. The Chrastil and Mendez-Santiago and Teja density-based models were applied to evaluate experimental data. The heat of solution $(\Delta H)$ of neem oil, azadirachtin, nimbin, and salannin in SC- $\mathrm{CO}_{2}$ was found to be $-28.79 \mathrm{~kJ} / \mathrm{mol},-42.33 \mathrm{~kJ} / \mathrm{mol},-35.98 \mathrm{~kJ} / \mathrm{mol}$, and $-51.69 \mathrm{~kJ} / \mathrm{mol}$, respectively. The consistency plots of Mendez-Santiago and Teja model were given to test its applicability in representing experimental data over a range of pressure and temperature studied.
\end{abstract}

(c) 2012 Elsevier B.V. All rights reserved.

\section{Introduction}

Azadirachta indica A. Juss, also known as neem, is a tree belongs to mahogany family (Meliaceae) that can grow in most dry, subtropical, and tropical climates. Neem tree is native to tropical South East Asia and usually found as a vegetation population part in the bush forest. Different parts of neem tree have been used since a long time for medicinal and agricultural purposes [1]. The leaves of neem tree (Azadirachta siamensis) are consumed as a vegetable by some local residents in Thailand country [2]. The seed contains around $15-45 \%$ edible oil $[2,3]$ that mainly composed of oleic acid (omega-9), linoleic acid (omega-6), palmitic acid, stearic acid, $\alpha$ linoleic acid (omega-3), and arachidic acid [2]. The concentration of oil and triterpenoid compounds in neem seed depends on the geographic location where the plant grown.

Many valuable bioactive substances from limonoids class of triterpenoids are found in neem oil such as azadirachtin (azadirachtin A), salannin, salannol, nimbin, nimbinin, nimbidin, nimbidiol, 3-tigloylazadirachtol (azadirachtin B), and 1-tigloyl-3acetyl-11-hydroxymeliacarpin (azadirachtin D) [2,4,5]. All these substances are known to pose strong biological properties against insects, larvae, fungi, etc. Among them, azadirachtin is a highly

\footnotetext{
* Corresponding author. Tel.: +62 31389 1264; fax: +62 313891267.

E-mail addresses: suryadiismadji@yahoo.com,

a1f1n_kwn@yahoo.com (S. Ismadji).
}

important and interesting compound to be studied with respect to its biological properties as a feeding deterrent and a growth disrupting for most insects and various kinds of arthropods [4]. As a natural pesticide, this compound has very low toxicity toward most vertebrates [4]. To this end, the identification of complex chemical structure of azadirachtin and its synthesis and purification have offered a great challenge to the chemists and biologist for more than 40 years.

Neem tree can be found easily in the eastern part of Indonesia (e.g., some area of East Java, Bali, Lombok, Sumbawa, Flores, etc.). Neem seed kernel from Indonesia, especially from Bali, contains significant amount of oil (around $40 \mathrm{wt} \%$ ) and up to $6200 \mathrm{ppm}$ of azadirachtin. Depending on the extraction method, the concentration of azadirachtin in crude neem oil may vary from $100 \mathrm{ppm}$ to more than $4000 \mathrm{ppm}$ [3,5-7]. In this regard, the most widely used method for extraction of neem oil from its seed kernel is mechanical pressing. However, the quality of resulted oil is poor to moderate with low concentration of azadirachtin and other bioactive compounds. To improve the quality of the oil, a more efficient and effective extraction method should be adapted.

In recent years, supercritical fluid extraction (SFE) has been highlighted as an effective and efficient method for the recovery of various bioactive compounds from plant or solid matrices. The applications of SFE have widely found in various industrial fields such as special chemicals, pharmaceuticals, food, etc. In this regard, carbon dioxide is often used as a supercritical solvent because it is inexpensive, non-toxic, and has low to moderate critical properties. 
The solvation properties of $\mathrm{SC}-\mathrm{CO}_{2}$ and other supercritical fluids can be tailored by adjusting pressure and temperature which make its uses as a solvent or co-reagent also feasible for other purposes (besides SFE) such as chromatographic separations [8,9], tissue engineering [10], sol-gel synthesis [11], biodiesel and nanoparticle productions [12,13], clean and green chemical processes [13-15], etc. The extraction of oil and several triterpenoids from neem seed using SC- $\mathrm{CO}_{2}$ has been reported in literatures [1,2,16-19]. However, a further study still needs to be conducted due to lack of solubility data over wide range of pressures and temperatures. For example, Johnson and Morgan [16] report SC- $\mathrm{CO}_{2}$ extraction of oil and several triterpenoids (azadirachtin, nimbin, and salannin) from neem seed at single temperature system (328.15 K). They used methanol as a co-solvent to improve the selectivity and extraction performance of triterpenoid compounds from the seed matrices. Another work conducted by Ambrosino et al. [17] reports single temperature $\mathrm{SC}-\mathrm{CO}_{2}$ extraction of neem oil, azadirachtin, nimbin, and salannin at $313.15 \mathrm{~K}$. While the lack of solubility data at various temperatures becomes the drawback of Johnson and Morgan and Ambrosino et al. works, Tonthubthimthong et al. [1,18], Mongkholkhajornsilp et al. [2], and Zahedi et al. [19] only focus on the $\mathrm{SC}-\mathrm{CO}_{2}$ extraction of nimbin from neem seeds with or without co-solvent.

In this work, the SC- $\mathrm{CO}_{2}$ extraction of oil and several triterpenoid compounds (azadirachtin, nimbin, and salannin) from neem seed kernel was performed at several temperatures $(313.15 \mathrm{~K}$, $323.15 \mathrm{~K}$, and $333.15 \mathrm{~K}$ ) and pressures (10-35 MPa) without involving any co-solvent. The effect of pressure and temperature on the extraction yields of oil and triterpenoids was studied. The Chrastil and Mendez-Santiago and Teja density-based model were used to evaluate experimental solubility data. A comparison study of extraction methods between cold-pressing, soxhlet extraction, and SC- $\mathrm{CO}_{2}$ extraction methods toward the quality of neem oil produced was also conducted and discussed comprehensively.

\section{Materials and methods}

\subsection{Materials}

Neem seed was obtained from Intaran Indonesia Co., Ltd. Bali, Indonesia. Prior to use, the seed was removed from its shell and repeatedly washed with tap water to remove surface dirt. Subsequently, the seed kernel was dried in a Lab-Line Duo-Vac Oven at $323.15 \mathrm{~K}$ for $24 \mathrm{~h}$ until its moisture content around $6-7 \%$. The dried seed kernel was then crushed using an IKA ${ }^{\circledR}$-Labortechnick grinder and stored in airtight plastic bags for further use.

Food grade $\mathrm{CO}_{2}$ (purity $\geq 99.95 \%$ ) was obtained from Aneka Gas Co., Ltd. East Java, Indonesia and supplied as liquid $\mathrm{CO}_{2}$ in the deep tube supply cylinder. Methanol (HPLC Grade) and n-hexane (A.R. Grade) were obtained from Merck, Germany. Analytical grade azadirachtin A (CAS Number 11141-17-6) was purchased from Sigma-Aldrich, Singapore and used as the standard reference for analysis of azadirachtin content.

\subsection{Extraction experiments}

In this work, the extraction of oil from neem seed kernel was performed in three ways namely cold-pressing, soxhlet extraction, and $\mathrm{SC}-\mathrm{CO}_{2}$ extraction. The cold-pressing of neem oil was performed in an Enerpac RC-256 hydraulic pressing system with single acting cylinder. The cylindrical pump was equipped with a $1.8 \mathrm{~m}$ safety hose with gauge adaptor. Twenty-five grams of neem seed kernels were loaded to the pressing canister and pressed at $6000 \mathrm{psi}$ for an hour in room temperature. The yield of neem oil was determined gravimetrically using an analytical mass balance (PRECISA 3000D).
The soxhlet extraction procedure was described as follows: $25 \mathrm{~g}$ of neem seed kernels was introduced into a $250 \mathrm{~mL}$ one neck round flask containing $100 \mathrm{~mL}$-hexane. The mixture was then heated in a Barnstead electrothermal EMA 500/CEB heating mantle at $343.15 \mathrm{~K}$ and stirred at $500 \mathrm{rpm}$ for $4 \mathrm{~h}$. The oily extract was then evaporated in an IKA ${ }^{\circledR} R V-10$ rotavapor under vacuum condition at $323.15 \mathrm{~K}$ to remove n-hexane. The amount of oil obtained was represented as $100 \%$ oil extraction.

The SC- $\mathrm{CO}_{2}$ extraction was performed in semi-pilot plat supercritical extraction equipment. The system consists of a high pressure piston pump with two inlets and outlets (Eldex AA100-S-2-CE, USA), a pressure transducer (Druck PTX 611, USA) equipped with digital indicator (Druck DPI 280, USA). To maintain isothermal condition, a temperature-programmed oven (Memmert) was used as an external heater. The uncertainty of pressure and temperature in the process was $\pm 0.01 \mathrm{MPa}$ and $\pm 1 \mathrm{~K}$, respectively. All the fittings and tubings used in the system were 316SS grade stainless steel (Swagelok, USA). The maximum working pressure and temperature of the system are $40 \mathrm{MPa}$ and $423.15 \mathrm{~K}$, respectively.

The experiments were conducted by loading $25 \mathrm{~g}$ of neem seed kernel into a $150 \mathrm{~cm}^{3}$ high pressure extraction column. The system was then evacuated by a vacuum pump (GAST DOA-P504 BN, USA) before heating. The evacuated column was then heated from room temperature to a desired temperature $(313.15 \mathrm{~K}, 323.15 \mathrm{~K}$, and $333.15 \mathrm{~K}$ ). Subsequently, liquid $\mathrm{CO}_{2}$ was flown into the column at a constant flow rate of $5 \mathrm{~cm}^{3} / \mathrm{min}$ (measured at $6.8 \mathrm{MPa}$ and $303.15 \mathrm{~K}$ by a volume calibrator) until desired pressure reached (10 MPa to $35 \mathrm{MPa}$ ). The process was run for $4 \mathrm{~h}$. A back-pressure valve at the outlet of the system was adjusted to maintain constant volume throughout the experiments. The resulted products that consisted of $\mathrm{SC}-\mathrm{CO}_{2}$, neem oil, and several triterpenoid compounds were bubbled into a collecting flask containing methanol.

The amount of azadirachtin in neem oil was analyzed by HPLC technique. The instrument consists of a Jasco PU-2089 plus quaternary gradient pump, a Jasco UV-2077 plus intelligent UV/VIS detector, and a Jasco LC-NetII/ADC for data acquisition. The stationary phase was a Luna C18(2) column $(250 \mathrm{~mm}$ in length $\times 4.6 \mathrm{~mm}$, i.d.) containing $5 \mu \mathrm{m}$ particles. The detail procedure for analysis of azadirachtin can be found elsewhere [5]. For reproducibility test, all experiments were replicated three times and the results were given as average \pm SD.

\section{Results and discussion}

\subsection{Evaluation of extraction methods on the yield of neem oil and azadirachtin content}

As mentioned above, the concentration of azadirachtin in neem oil strongly depends on the extraction method used. In cold pressing method, the extraction of oil from neem seed kernel occurs as a result of mechanical action that causes the breakdown of internal structure of the solid and diminishing of most voids. The amount of neem oil recovered by this method was $82 \%$. However, the quality of resulted oil is poor due to low content of azadirachtin $(1427 \pm 51 \mathrm{ppm})$ with percentage recovery of $25.3 \%$. This result may reveal a non-selective behavior of extraction process by mechanical means. Although cold pressing method offers several advantages such as low capital investment and operational cost, ease of operation, and does not need any solvent recovery process, however, the intensive purification steps required to obtain high quality oil often reduce triterpenoid contents and may pose technical and economic constraints for large scale operation. The yield of neem oil obtained from soxhlet extraction method was $9.57 \pm 0.34 \mathrm{~g}$ which corresponds to percentage recovery of $92.3-99.1 \%$. The azadirachtin 
Table 1

The percentage recovery of neem oil and several triterpenoids at various pressures and temperatures.

\begin{tabular}{|c|c|c|c|c|c|c|}
\hline \multirow[t]{2}{*}{$T(\mathrm{~K})$} & \multirow[t]{2}{*}{$P(\mathrm{MPa})$} & \multicolumn{5}{|c|}{ Percentage recovery (\%) } \\
\hline & & Neem oil $\left(\times 10^{3} \mathrm{~kg}\right)$ & Azadirachtin (ppm) & Azadirachtin $\left(\times 10^{6} \mathrm{~kg}\right)$ & Nimbin $\left(\times 10^{6} \mathrm{~kg}\right)$ & Salannin $\left(\times 10^{6} \mathrm{~kg}\right)$ \\
\hline \multirow[t]{6}{*}{313.15} & 10 & $0.77 \pm 0.02$ & $1021 \pm 13$ & $0.94 \pm 0.04$ & $0.12 \pm 0.03$ & $0.28 \pm 0.05$ \\
\hline & 15 & $1.04 \pm 0.05$ & $1074 \pm 24$ & $1.33 \pm 0.09$ & $0.21 \pm 0.02$ & $0.33 \pm 0.03$ \\
\hline & 20 & $1.96 \pm 0.04$ & $1291 \pm 11$ & $3.01 \pm 0.08$ & $0.27 \pm 0.04$ & $0.37 \pm 0.04$ \\
\hline & 25 & $4.44 \pm 0.12$ & $1529 \pm 39$ & $8.06 \pm 0.36$ & $0.38 \pm 0.03$ & $0.41 \pm 0.06$ \\
\hline & 30 & $5.49 \pm 0.14$ & $1948 \pm 12$ & $12.73 \pm 0.25$ & $0.52 \pm 0.05$ & $0.55 \pm 0.02$ \\
\hline & 35 & $5.93 \pm 0.19$ & $2216 \pm 14$ & $15.65 \pm 0.59$ & $0.77 \pm 0.06$ & $0.61 \pm 0.06$ \\
\hline \multirow[t]{6}{*}{323.15} & 10 & $0.73 \pm 0.03$ & $1107 \pm 8$ & $0.96 \pm 0.04$ & $0.10 \pm 0.02$ & $0.27 \pm 0.06$ \\
\hline & 15 & $0.85 \pm 0.04$ & $1258 \pm 8$ & $1.27 \pm 0.05$ & $0.16 \pm 0.04$ & $0.35 \pm 0.04$ \\
\hline & 20 & $2.09 \pm 0.07$ & $1354 \pm 14$ & $3.37 \pm 0.11$ & $0.39 \pm 0.03$ & $0.61 \pm 0.03$ \\
\hline & 25 & $4.68 \pm 0.09$ & $1621 \pm 19$ & $9.04 \pm 0.27$ & $0.46 \pm 0.06$ & $0.73 \pm 0.03$ \\
\hline & 30 & $5.76 \pm 0.13$ & $2047 \pm 6$ & $14.03 \pm 0.27$ & $0.61 \pm 0.03$ & $0.92 \pm 0.02$ \\
\hline & 35 & $6.22 \pm 0.07$ & $2309 \pm 21$ & $18.47 \pm 0.36$ & $0.89 \pm 0.04$ & $1.05 \pm 0.08$ \\
\hline \multirow[t]{6}{*}{333.15} & 10 & $0.56 \pm 0.03$ & $1181 \pm 26$ & $0.79 \pm 0.03$ & $0.11 \pm 0.02$ & $0.26 \pm 0.05$ \\
\hline & 15 & $0.67 \pm 0.03$ & $1293 \pm 17$ & $1.03 \pm 0.04$ & $0.12 \pm 0.03$ & $0.37 \pm 0.03$ \\
\hline & 20 & $2.40 \pm 0.12$ & $1394 \pm 8$ & $3.98 \pm 0.18$ & $0.47 \pm 0.03$ & $0.82 \pm 0.08$ \\
\hline & 25 & $4.91 \pm 0.09$ & $1688 \pm 18$ & $9.87 \pm 0.25$ & $0.59 \pm 0.05$ & $1.07 \pm 0.07$ \\
\hline & 30 & $6.01 \pm 0.06$ & $2145 \pm 48$ & $15.35 \pm 0.45$ & $0.74 \pm 0.04$ & $1.42 \pm 0.12$ \\
\hline & 35 & $6.67 \pm 0.12$ & $2391 \pm 48$ & $18.99 \pm 0.60$ & $0.98 \pm 0.07$ & $1.57 \pm 0.06$ \\
\hline
\end{tabular}

content in the oily extract (after evaporation) was three folds higher $(4658.4 \pm 92.5 \mathrm{ppm})$ than that obtained from cold pressing method.

The percentage recovery of neem oil and azadirachtin at various pressures and temperatures is shown in Table 1. It can be seen that the percentage recovery of all substances was increased with increasing pressure at constant temperature. This is due to greater solvent density (solvating power) of $\mathrm{CO}_{2}$ at higher pressure that improves mass transfer and enhances solubility of solute in the solvent. This result was in agreement with previous works reported on the SC- $\mathrm{CO}_{2}$ extraction of several seed oils [20-23]. At pressures above $20 \mathrm{MPa}$, the solubility of neem oil increases with temperature increase, denoting the crossover pressure region (Fig. 1). The solubility increase of neem oil above the crossover pressure region is likely due to the reduced viscosity and the increased diffusivity coefficient of $\mathrm{SC}-\mathrm{CO}_{2}$ at higher temperature. Similar result was also observed by Salgin and Korkmaz [21] that studies supercritical desorption of pumpkin seed oil.

The effect of pressure and temperature on the percentage recovery of azadirachtin is shown in Fig. 2. A crossover pressure region for the recovery of azadirachtin was noticed at pressures around $20 \mathrm{MPa}$. Above this region, the increase of pressure from $25 \mathrm{MPa}$ to $35 \mathrm{MPa}$ would enhance the percentage recovery of azadirachtin almost two folds in each temperature. However, increasing temperature above the crossover pressure region would not give

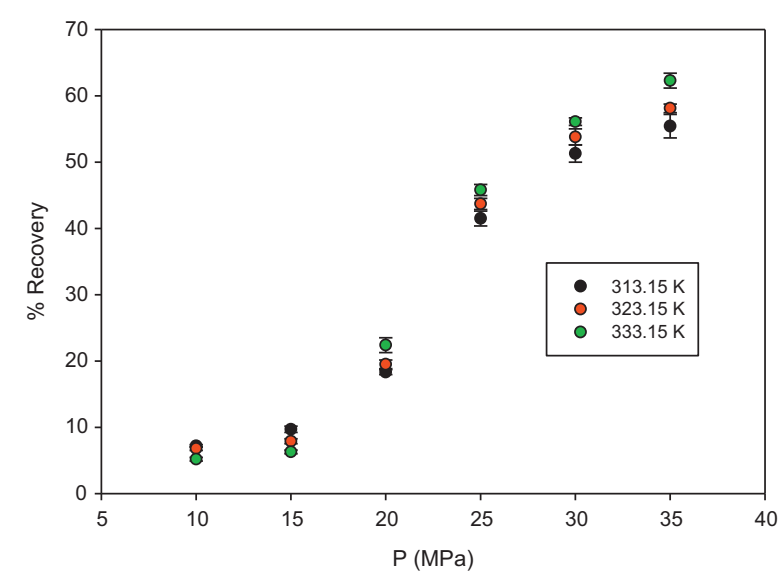

Fig. 1. The percentage recovery of neem oil by $\mathrm{SC}-\mathrm{CO}_{2}$ at various pressures and temperatures. significant increase on the percentage recovery of azadirachtin, revealing a poor effect of vapor pressure of the solute within this region (25-35 MPa). The presence of several triterpenoid compounds such as nimbin and salannin were also noted and the results are given in Table 1 . The percentage recovery of these substances in $\mathrm{SC}-\mathrm{CO}_{2}$ also increases with increasing pressure and temperature (Table 1). Since the focus of this work lies in the recovery of azadirachtin, the recovery of nimbin and salannin will not be discussed further.

By comparing the amount of neem oil recovered from solvent extraction using n-hexane and $\mathrm{SC}-\mathrm{CO}_{2}$, the later gives lower percentage recovery over a range of temperature and pressure studied. These results are below our expectation since neem oil is readily soluble in nonpolar solvent such as $\mathrm{CO}_{2}$. This is likely due to lower solvating power of $\mathrm{SC}-\mathrm{CO}_{2}$ than $\mathrm{n}$-hexane or less frequent contact between solute and solvent in the process. As mentioned above, the solvating power of $\mathrm{SC}-\mathrm{CO}_{2}$ increases when the density of fluid approaches the density of liquid solvent. The density of $\mathrm{SC}-\mathrm{CO}_{2}$ at $333.15 \mathrm{~K}$ and $35 \mathrm{MPa}$ was $877 \mathrm{~kg} / \mathrm{m}^{3}$ (calculated by Stryjek and Vera modification of Peng-Robinson (PRSV) equation of state) [24]. This value is higher than the density of n-hexane $\left(654.8 \mathrm{~kg} / \mathrm{m}^{3}\right)$ at atmospheric pressure hence higher solvating power of $\mathrm{SC}-\mathrm{CO}_{2}$ than n-hexane and the amount of neem oil recovered at this condition should be higher or at least similar with soxhlet extraction method.

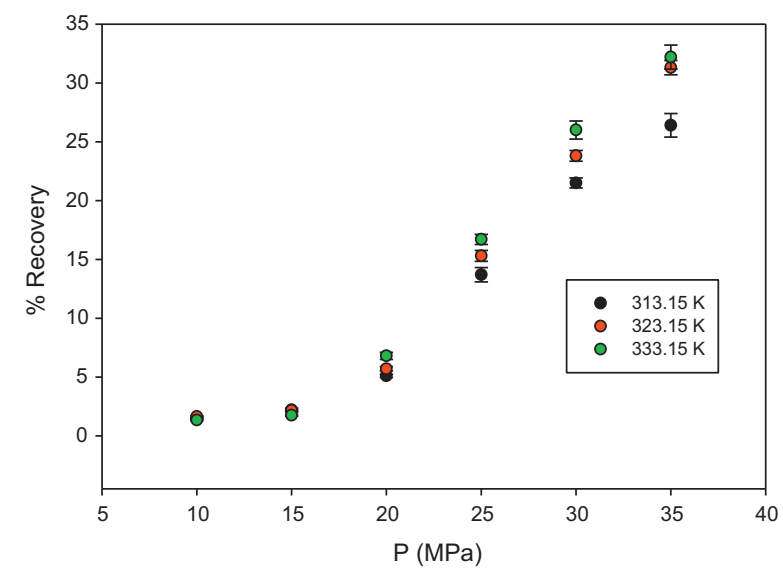

Fig. 2. The percentage recovery of azadirachtin by $\mathrm{SC}-\mathrm{CO}_{2}$ at various pressures and temperatures. 
Compared to cold pressing, $\mathrm{SC}-\mathrm{CO}_{2}$ extraction gives lower percentage recovery of oil, likely due to different mechanism of the extraction process. The extraction of oil by cold pressing method proceeds as a result of breakdown of internal structure of the solid and diminishing of most voids. In the SC- $\mathrm{CO}_{2}$ extraction, the recovery mechanism of oil is completely different with cold pressing method. There are several phenomena occurring such as diffusion, adsorption, formation of liquid film, dissolution, convective transport, and desorption [2]. In this case, the solubility of oil is not only depends on pressure and temperature, but also on the pore structure of the solid matrices. It is apparent that pressure cannot breakdown the internal structure of the solid therefore some amounts of the oil trapped in the inner part of solid matrices are difficult to be recovered.

The concentration of azadirachtin in the oil obtained from SC$\mathrm{CO}_{2}$ extraction was higher than those obtained by cold pressing and soxhlet extraction. Moreover, the physical appearance of the oil is much better than that obtained from cold pressing. In the supercritical condition, the solvating power of the fluid approaches that of the liquid solvent while the penetration ability in the solid matrix is facilitated by the gas-like transport properties. The dissolution of solutes in supercritical fluids results from a combination of vapor pressure and solute-solvent interaction effects. Therefore, the amount of azadirachtin recovered in the $\mathrm{SC}-\mathrm{CO}_{2}$ extraction was higher compared with that from mechanical pressing.

For comparison purpose, the results obtained by Johnson and Morgan [16] and Ambrosino et al. [17] were given in this work. The amount of azadirachtin obtained in this study at $313.15 \mathrm{~K}$ and $30 \mathrm{MPa}$ using mass ratio of $\mathrm{CO}_{2} /$ neem seed of 45 was $5.59 \times 10^{-4} \mathrm{~kg} / \mathrm{kg}$ seed. This value is slightly lower than the result obtained by Ambrosino et al. at the same temperature and pressure. In their works, the amount of azadirachtin obtained at $313.15 \mathrm{~K}$ and $30 \mathrm{MPa}$ was $6.39 \times 10^{-4} \mathrm{~kg} / \mathrm{kg}$ seed using $\mathrm{CO}_{2} /$ neem seed mass ratio of 64 . They also reported that increasing mass ratio of $\mathrm{CO}_{2} /$ neem seed to 119 , the amount of azadirachtin recovered was raised about three and a half folds $\left(2.291 \times 10^{-3} \mathrm{~kg} / \mathrm{kg}\right.$ seed $)$ than that obtained at mass ratio of $\mathrm{CO}_{2} /$ neem seed of 64 . Therefore, lower percentage recovery of azadirachtin in this work is caused by lower mass ratio of solvent/solute used compared to Ambrosino et al. work.

In supercritical fluid extraction, the use of co-solvent may give a crucial role in improving the amount of compounds obtained. Johnson and Morgan [16] studied the effect of methanol as co-solvent on the $\mathrm{SC}-\mathrm{CO}_{2}$ extraction of neem oil along with azadirachtin, nimbin, and salannin. As comparison, the percentage recovery of oil and azadirachtin obtained in this work was higher than Johnson and Morgan results [16]; however, vice versa phenomena were noticed in the percentage recovery of nimbin and salannin. By adding methanol as co-solvent, the polarity of $\mathrm{SC}-\mathrm{CO}_{2}$ was enhanced hence the polar compounds can dissolve better. Since nimbin and salannin have higher polarity than neem oil and azadirachtin, the solubility of the latter substances in supercritical $\mathrm{CO}_{2}$-methanol was lower than the former. In this work, we did not perform SFE with cosolvent because such procedure may not practical for industrial scale operation and requires further purification steps to separate co-solvent and the desired products.

\subsection{Correlations of solubility data of neem oil and several triterpenoids in $\mathrm{SC}-\mathrm{CO}_{2}$}

The solubility of solute in supercritical fluid is not only a simple function of pressure, but also depends on temperature. In this regard, several empirical and semi-empirical models have been developed to correlate and extrapolate experimental solubility data at various pressures and temperatures. Most of the solubility-based models were developed based on the two approaches: (1) Equation of State (EOS) or (2) density-based correlation. In the first case,
Table 2

The density of $\mathrm{SC}-\mathrm{CO}_{2}$ at various pressures and temperatures.

\begin{tabular}{lll}
\hline$T(\mathrm{~K})$ & $P(\mathrm{MPa})$ & $\rho\left(\mathrm{kg} / \mathrm{m}^{3}\right)^{\mathrm{a}}$ \\
\hline 313.15 & 10 & 565 \\
& 15 & 748 \\
& 20 & 830 \\
25 & 886 \\
& 30 & 929 \\
& 35 & 963 \\
323.15 & 10 & 376 \\
& 15 & 657 \\
& 20 & 764 \\
& 25 & 831 \\
333.15 & 30 & 881 \\
& 35 & 920 \\
& 10 & 293 \\
& 15 & 562 \\
& 20 & 695 \\
& 25 & 775 \\
& 30 & 832 \\
& 35 & 877 \\
\hline
\end{tabular}

a Calculated by PRSV equation of state [24].

a number of EOS models have been tested to represent various experimental data, however, the applicability of each EOS model is limited to certain groups of compounds and process conditions. The most extensively used EOS are two-parameter cubic equations of state coupled with different mixing rules. However, the choice of the most suitable EOS for a certain solute-SCF system is empirical and it must be noted that no single EOS will work generally for all systems. In the second case, the density-based model was developed based on the common observation that the logarithm of solubility is linearly dependent on the density. The use of density-based model to correlate solubility data offers an advantage because such model does not require any thermophysical data of the compound investigated.

Chrastil [25] was the first who develops the density-based model in 1982 to correlate solubility data of many solids and liquids in supercritical fluids. He assumed that association of solute and solvent occurs to form a solvato complex and the solvato complex was in equilibrium with the solute and solvent molecules. The density-based model developed by Chrastil has mathematical form as follow:

$C=\rho^{k} \exp \left(\frac{a}{T}+b\right)$

where $C$ is the concentration of solute in supercritical fluid $\left(\mathrm{kg} / \mathrm{m}^{3}\right)$, $\rho$ is the density of supercritical fluid $\left(\mathrm{kg} / \mathrm{m}^{3}\right), k$ is an association constant, $a$ is a function of the enthalpy of solvation $\left(\Delta H_{\text {solv }}\right)$ and the enthalpy of vaporization ( $\Delta H_{\mathrm{vap}}$ ), and $b$ is a function of association constant that depends on the molecular weight and the melting point of solute and the fluid [25].

The parameter values of $k, a$, and $b$ are specific for each solute-solvent system and independent with temperature. In this work, these parameters were simultaneously determined through nonlinear least square fitting against experimental data at various temperatures. The following equation was employed as an objective function to be minimized:

$\mathrm{SSE}=\left(\frac{\left(\sum C_{\mathrm{exp}}-C_{\mathrm{cal}}\right)^{2}}{N}\right)^{1 / 2}$

Here, $C_{\exp }$ and $C_{\text {cal }}$ are the actual and calculated solubility, respectively and $N$ is the number of experimental data.

PRSV (Peng-Robinson-Stryjek-Vera) equation of state [24] was used to calculate the density of $\mathrm{SC}-\mathrm{CO}_{2}$ at various pressures and temperatures (Table 2). This EOS was selected because of its good 

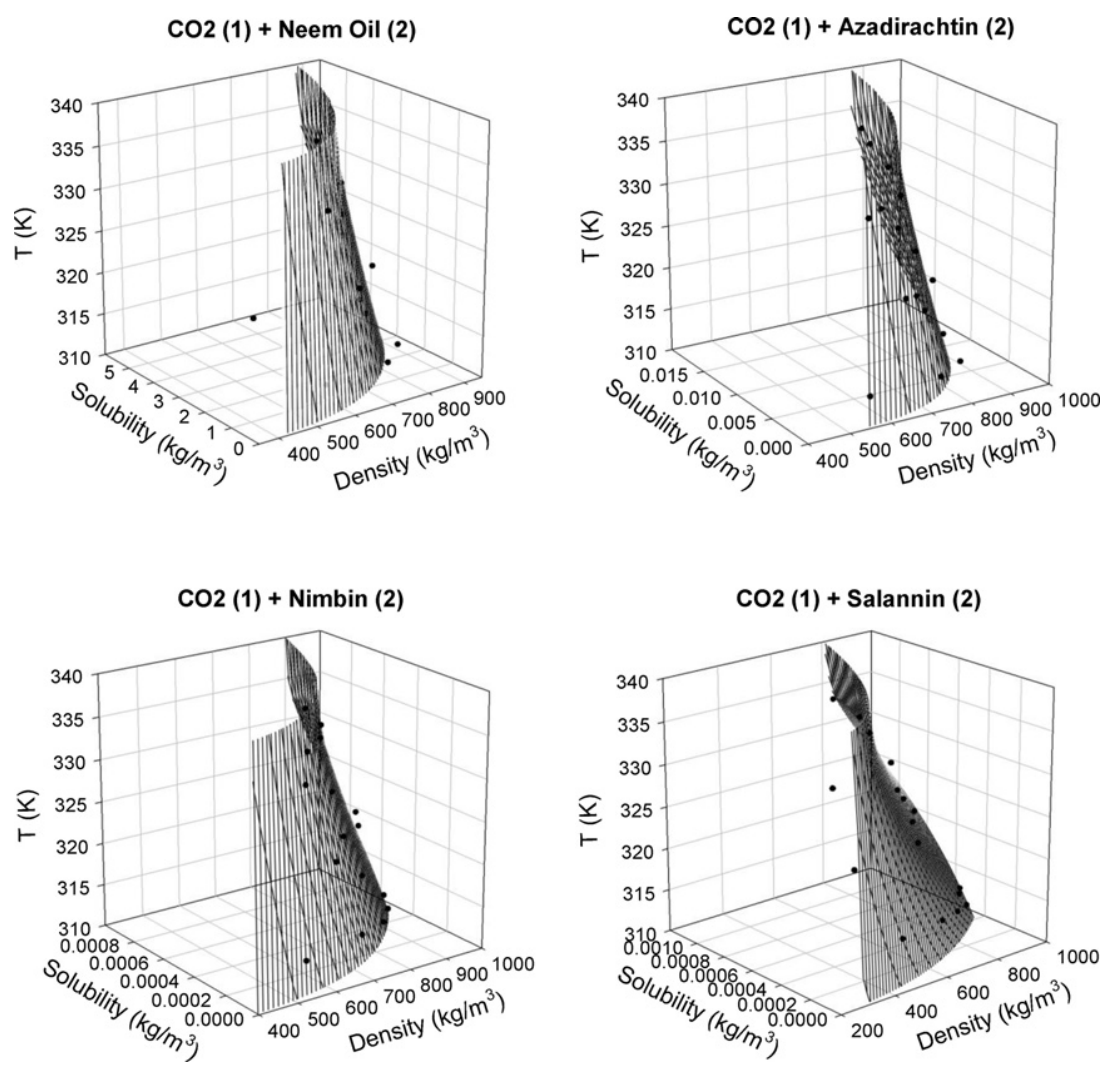

Fig. 3. The $3 \mathrm{D}$ mesh plots of Chrastil model fitting for experimental solubility data of neem oil and several triterpenoids in $\mathrm{SC}^{-\mathrm{CO}_{2}}$

accuracy in describing the behavior of fluids in moderately nonideal systems with a relatively small deviation (within $6 \%$ or less). In addition, this EOS is easy to use because it only needs the critical properties and acentric factor for the generalized parameters. Fig. 3 shows 3D mesh plots of solubility of neem oil and several triterpenoids in $\mathrm{SC}-\mathrm{CO}_{2}$ as a function of density and temperature. The experimental data and the model fitting were designated as dot symbol and wire-mesh line, respectively. The Chrastil solubility parameters for $\mathrm{CO}_{2}$-neem oil, $\mathrm{CO}_{2}$-azadirachtin, $\mathrm{CO}_{2}$-nimbin, and $\mathrm{CO}_{2}$-salannin systems are given in Table 3 .

The association of one solute molecule with a number of $\mathrm{CO}_{2}$ molecules to form a solvato complex was represented as parameter $k$. If the equilibrium condition in the system is reached, the formation of solvato complex can be written as follows [25]:

$A+k B \Leftrightarrow A B_{k}$

Table 3

The fitted solubility parameters of Chrastil model for various systems.

\begin{tabular}{|c|c|c|c|c|c|}
\hline \multirow[t]{2}{*}{ Systems } & \multirow[t]{2}{*}{$T(\mathrm{~K})$} & \multicolumn{3}{|c|}{ Parameters } & \multirow[t]{2}{*}{ SSE } \\
\hline & & $a$ & $b$ & $k$ & \\
\hline $\mathrm{CO}_{2}$-neem oil & $\begin{array}{l}313.15 \\
323.15 \\
333.15\end{array}$ & -3462.74 & -20.82 & 4.86 & 0.448 \\
\hline $\mathrm{CO}_{2}$-azadirachtin & $\begin{array}{l}313.15 \\
323.15 \\
333.15\end{array}$ & -5090.89 & -38.21 & 7.32 & 0.0011 \\
\hline $\mathrm{CO}_{2}$-nimbin & $\begin{array}{l}313.15 \\
323.15 \\
333.15\end{array}$ & -4327.25 & -24.02 & 4.41 & $5.96 \times 10^{-5}$ \\
\hline $\mathrm{CO}_{2}$-salannin & $\begin{array}{l}313.15 \\
323.15 \\
333.15\end{array}$ & -6217.51 & -6.15 & 2.68 & $7.26 \times 10^{-5}$ \\
\hline
\end{tabular}

where $A$ is the solute, $B$ is the supercritical fluid, and $A B$ is the solvato complex. The formation of solvato complex proceeds simultaneously where some of them are more stable while others are less stable. Therefore, an integer value of $k$ cannot be determined precisely since the formation of solvato complexes is not stoichiometrically occurred [25]. In most cases, the parameter $k$ was expressed as an average equilibrium number that is the characteristic constant for a given fluid and solute. The association constant $(k)$ for $\mathrm{CO}_{2}$-azadirachtin system was 7.32. This value is significantly different with our previous result $(k=2.54)$. In our previous work [26], we used pure azadirachtin as the solute thus only two components are presented in the system. A completely different condition was applied in this work since other triterpenoids (nimbin and salannin) were included in the system hence multiple solute-solvent interactions between $\mathrm{CO}_{2}$ and these compounds (including azadirachtin) may occur. Moreover, the formation of solvato complexes also takes place simultaneously with other components. Accordingly, higher value of association constant for $\mathrm{CO}_{2}$-azadirachtin system in this work.

The parameter $a$ is a function of enthalpy of solvation and enthalpy of vaporization and can be expressed as $a=\Delta H / R$ where $\Delta H$ is the total heat of reaction or heat of solution ( $\Delta H=\Delta H_{\text {solv }}+\Delta H_{\text {vap }}$ ) and $R$ is the universal gas constant $(8.314 \mathrm{~J} / \mathrm{mol} \mathrm{K})$. The heat of solution of neem oil, azadirachtin, nimbin, and salannin was found to be $-28.79,-42.33,-35.98$, and $-51.69 \mathrm{~kJ} / \mathrm{mol}$, respectively. The heat of solution of azadirachtin in $\mathrm{SC}-\mathrm{CO}_{2}$ in this work also differs greatly with our previous result $(-42.33 \mathrm{~kJ} / \mathrm{mol}$ vs. $-26.33 \mathrm{~kJ} / \mathrm{mol})$, likely due to higher value of association parameter. To this end, all magnitude values of fitted Chrastil solubility parameters $(a, b$, and $k$ ) for $\mathrm{CO}_{2}$-neem oil, $\mathrm{CO}_{2}$-azadirachtin, $\mathrm{CO}_{2}$-nimbin, and $\mathrm{CO}_{2}$-salannin systems were in conformance with those reported previously in literatures [27-35]. 

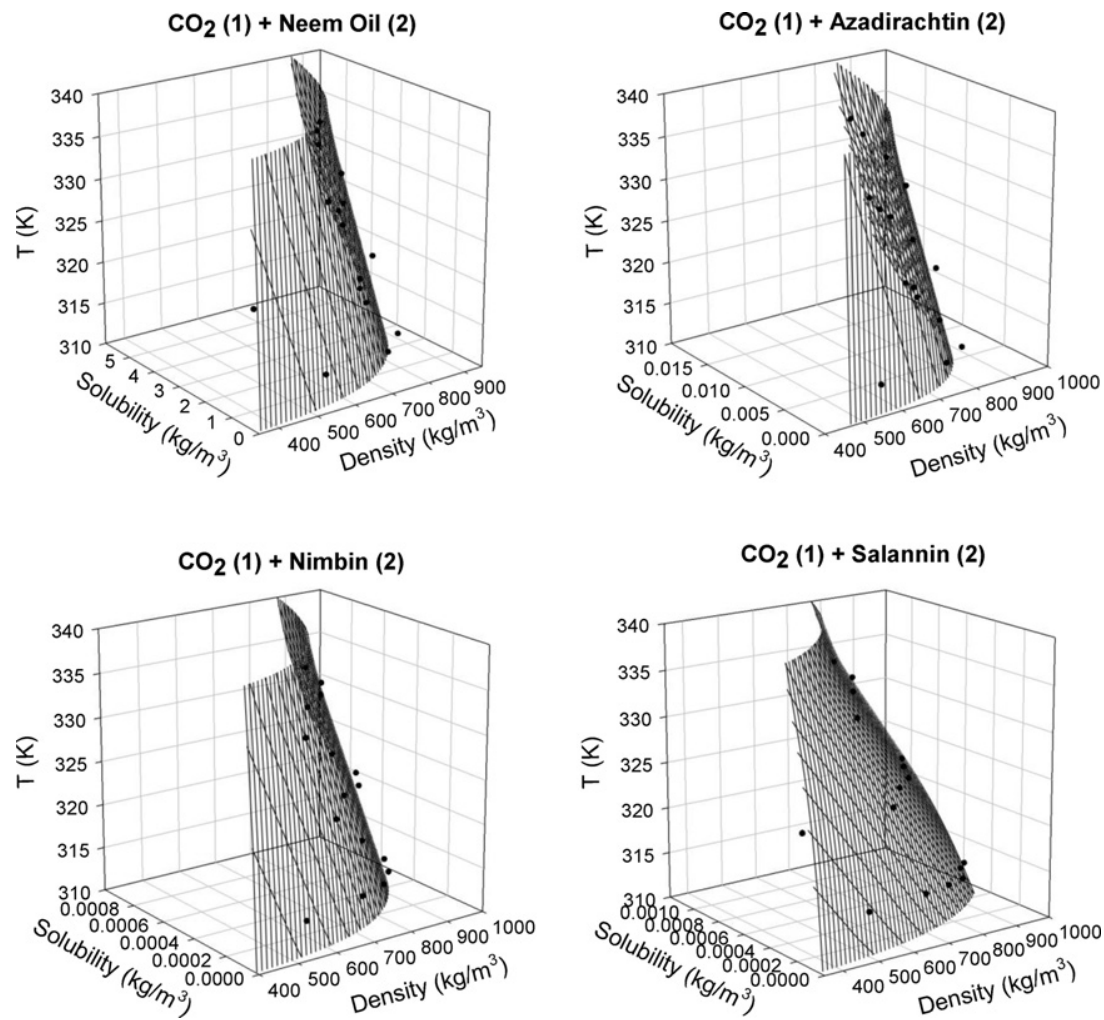

Fig. 4. The 3D mesh plots of Mendez-Santiago and Teja model fitting for experimental solubility data of neem oil and several triterpenoids in $\mathrm{SC}^{-\mathrm{CO}_{2}}$.
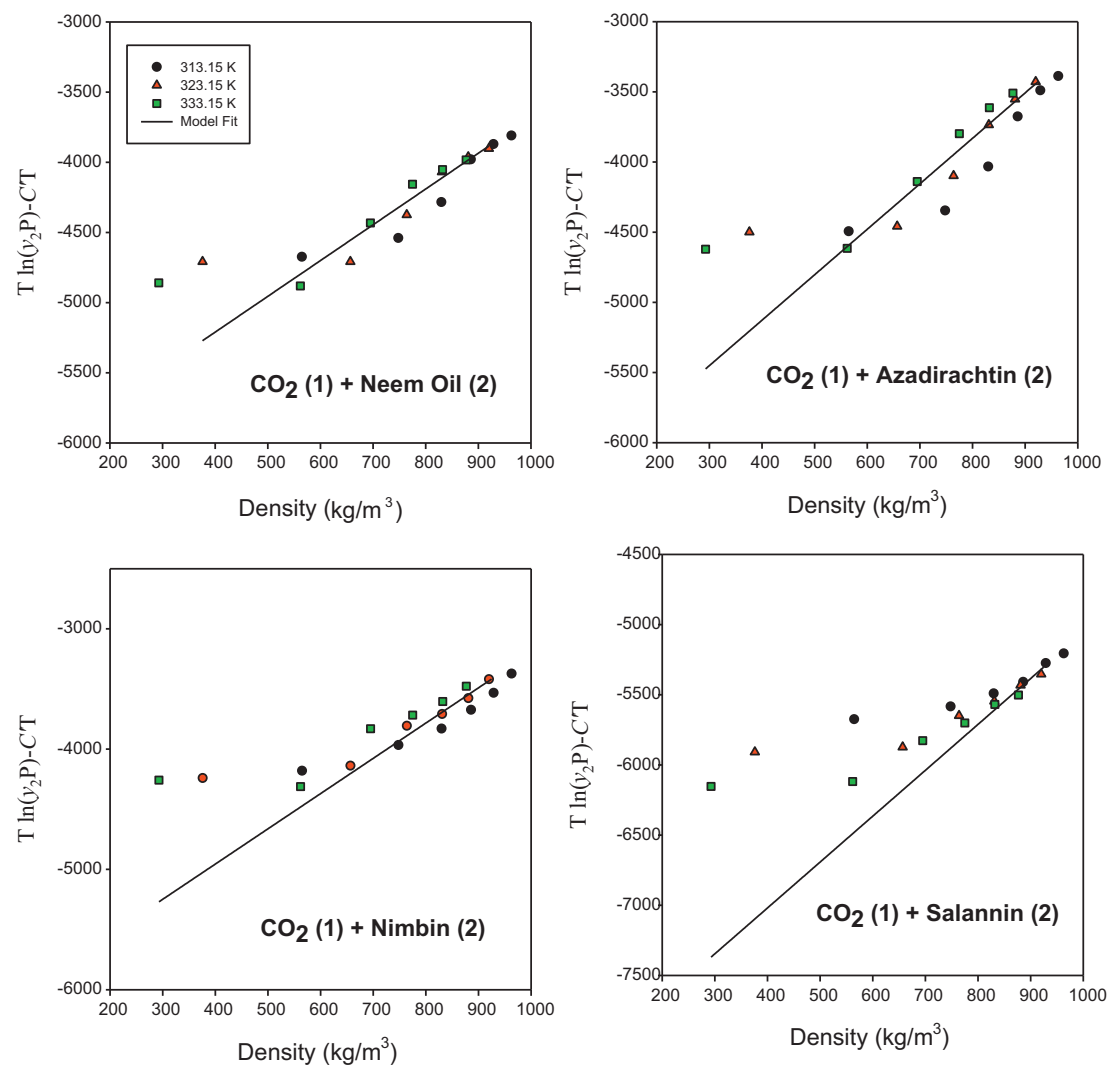

Fig. 5. The consistency plots of Mendez-Santiago and Teja model for correlation of experimental solubility data of neem oil and several triterpenoids in SC-CO ${ }_{2}$. 
Table 4

The fitted solubility parameters of Mendez-Santiago and Teja model for various systems.

\begin{tabular}{llllll}
\hline \multirow{2}{*}{ Systems } & $T(\mathrm{~K})$ & \multicolumn{2}{l}{ Parameters } & \multicolumn{2}{l}{ SSE } \\
\cline { 3 - 5 } & & $A^{\prime}$ & $B^{\prime}$ & \multicolumn{1}{l}{$C^{\prime}$} & \\
\hline $\mathrm{CO}_{2}$-neem oil & 313.15 & -5300.94 & 1.92 & 12.57 & 0.441 \\
& 323.15 & & & & \\
& 333.15 & & & & \\
$\mathrm{CO}_{2}$-azadirachtin & 313.15 & -7823.48 & 2.83 & 12.16 & 0.001 \\
& 323.15 & & & & \\
$\mathrm{CO}_{2}$-nimbin & 333.15 & & & & \\
& 313.15 & -6087.49 & 1.80 & 6.44 & \multirow{2}{*}{$4.96 \times 10^{-5}$} \\
& 323.15 & & & & \\
$\mathrm{CO}_{2}$-salannin & 333.15 & & & & \\
& 313.15 & -7431.73 & 1.19 & 12.56 & $6.04 \times 10^{-5}$ \\
& 323.15 & & & & \\
\hline
\end{tabular}

Mendez-Santiago and Teja [36] proposed a density-based model based on the dilute solution theory and expressed the mathematic model as follow:

$T \ln E=T \ln \frac{y_{2} P}{P_{2}^{\text {Sub }}}=A+B \rho_{1}$

Here, $P$ and $P_{2}^{\text {Sub }}$ are the total pressure and the sublimation pressure of the solute, respectively. The parameter $y_{2}$ refers to the solute fraction, $\rho_{1}$ is the density of supercritical fluid, $A$ and $B$ are constant parameters, and $E$ is the enhancement factor that defines as the ratio of actual solubility to the ideal solubility. Since the sublimation pressure of all triterpenoids and neem oil studied are not available, a modified Mendez-Santiago and Teja model was applied to evaluate experimental data, as given below:

$T \ln y_{2} P=A^{\prime}+B^{\prime} \rho_{1}+C^{\prime} T$

where $A^{\prime}, B^{\prime}$, and $C^{\prime}$ are the constant parameters.

Since the molecular weight of neem oil is unknown, we present the solubility of all substances $\left(y_{2}\right)$ in mass fraction unit. The constant parameters of Mendez-Santiago and Teja model obtained from simultaneous nonlinear least square fitting of experimental data are presented in Table 4 while 3D mesh plots of the model fitting are displayed in Fig. 4. In this figure, it can be seen that Mendez-Santiago and Teja model can represent experimental data fairly well, as indicated from small values of SSE. The consistency plots of Mendez-Santiago and Teja model was also given to test the applicability of the model (Fig. 5). It can be seen that this model can represent experimental data satisfactorily at pressures above $20 \mathrm{MPa}$ (in the density region above $700 \mathrm{~kg} / \mathrm{m}^{3}$ ) over temperature range studied. However, at lower pressure (below $20 \mathrm{MPa}$ ), this model loses its accuracy in predicting experimental solubility data, especially for $\mathrm{CO}_{2}$-nimbin and $\mathrm{CO}_{2}$-salannin systems.

\section{Conclusions}

In this work, the extraction of oil and several triterpenoids (azadirachtin, nimbin, and salannin) from neem seed kernel using $\mathrm{SC}-\mathrm{CO}_{2}$ at various temperatures and pressures has been conducted. The effect of pressure and temperature was found to be important in increasing the percentage recovery of the studied compounds. The crossover pressure region for $\mathrm{CO}_{2}$-neem oil and $\mathrm{CO}_{2}$-azadirachtin systems was observed at pressures around $20 \mathrm{MPa}$. The evaluation of experimental solubility data by Chrastil density-based model could be used to interpret the associative interaction between solute and solvent in supercritical state. The heat of solution $(\Delta H)$ of neem oil, azadirachtin, nimbin, and salannin in $\mathrm{SC}-\mathrm{CO}_{2}$ was found to be $-28.79 \mathrm{~kJ} / \mathrm{mol},-42.33 \mathrm{~kJ} / \mathrm{mol}$, $-35.98 \mathrm{~kJ} / \mathrm{mol}$, and $-51.69 \mathrm{~kJ} / \mathrm{mol}$, respectively. The consistency plots of Mendez-Santiago and Teja model show good correlation results between experimental data and the model in high pressure region (above $20 \mathrm{MPa}$ ) over temperature range studied. To this end, this work gives interesting information to the readership for the extraction of several valuable triterpenoids from neem seed kernel using SC- $\mathrm{CO}_{2}$ in the absence of co-solvent.

\section{Acknowledgement}

This work was supported by Directorate General of Higher Education, Indonesia Ministry of Education through a Competency Grant 2010 with contract number of 385/SP2H/PL/Dit.Litabmas/VI/2011.

\section{References}

[1] P. Tonthubthimthong, S. Chuaprasert, P. Douglas, W. Luewisutthichat, J. Food Eng. 47 (2001) 289-293.

[2] D. Mongkholkhajornsilp, S. Douglas, P.L. Douglas, A. Elkamel, W. Teppaitoon, S Pongamphai, J. Food Eng. 71 (2005) 331-340.

[3] T. Satyanandam, G. Rosaiah, K. Babu, Y.S. Rao, K.R.S.S. Rao, Indian Curr. Trend Biotechnol. Pharm. 5 (2011) 1029-1037.

[4] E.D. Morgan, Bioorgan. Med. Chem. 17 (2009) 4096-4105.

[5] E. Melwita, Y.H. Ju, Sep. Purif. Technol. 74 (2010) 219-224.

[6] O.P. Sidhu, V. Kumar, H.M. Behl, Variability in neem (Azadirachta indica) with respect to azadirachtin content, J. Agric. Food Chem. 51 (2003) 910-915.

[7] M.R. Forim, M.F.D.G.F. Da Silva, Q.B. Cass, J.B. Fernandes, P.C. Vieira, Anal. Methods 2 (2010) 860-869.

[8] W. Ren-Qi, O.Teng-Teng, N. Siu-Choon, T. Weihua, Trends Anal.Chem. 37 (2012) 83-100.

[9] D. Thiebaut, J. Chromatogr. A 1252 (2012) 177-188.

[10] E. Reverchon, S. Cardea, J. Supercrit. Fluids 69 (2012) 97-107.

[11] R. Sui, P. Charpentier, Chem. Rev. 112 (2012) 3057-3082.

[12] L. Soh, J. Zimmerman, Green Chem. 13 (2011) 1422-1429.

[13] P. Sheth, H. Sandhu, D. Singhal, W. Malick, N. Shah, M.S. Kislalioglu, Curr. Drug Deliv. 9 (2012) 269-284.

[14] H. Machida, M. Takesue, R.L. Smith, J. Supercrit. Fluids 60 (2011) 2-15.

[15] M. Perrut, J. Supercrit. Fluids 66 (2012) 359-371.

[16] S. Johnson, E.D. Morgan, Phytochem. Anal. 8 (1997) 228-232.

[17] P. Ambrosino, R. Fresa, V. Fogliano, S.M. Monti, A. Ritieni, J. Agric. Food Chem. 47 (1999) 5252-5256.

[18] P. Tonthubthimthong, P.L. Douglas, S. Douglas, W. Luewisutthichat, W. Teppaitoon, L. Pengsopa, J. Supercrit. Fluids 30 (2004) 287-301.

[19] G. Zahedi, A. Elkamel, A. Lohi, J. Food Eng. 97 (2010) 127-134.

[20] U. Salgin, O. Doker, A. Calimli, J. Supercrit. Fluids 38 (2006) 326-331.

[21] U. Salgin, H. Korkmaz, J. Supercrit. Fluids 58 (2011) 239-248.

[22] H. Mhemdi, E. Rodier, N. Kechaou, J. Fages, J. Food Eng. 105 (2011) 609-616.

[23] G. Zahedi, A. Azarpour, J. Supercrit. Fluids 58 (2011) 40-48.

[24] R. Stryjek, J.H. Vera, Can. J. Chem. Eng. 64 (1986) 323-333.

[25] J. Chrastil, J. Phys. Chem. 86 (1982) 3016-3021.

[26] S. Ismadji, Y.H. Ju, F.E. Soetaredjo, A. Ayucitra, J. Chem. Eng. Data 56 (2011) 4549-4555.

[27] Y. Yamini, M. Moradi, J. Chem. Thermodyn. 43 (2011) 1091-1096.

[28] P. Dong, M. Xu, X. Lu, C. Lin, Fluid Phase Equilibr. 297 (2010) 46-51.

[29] X.Y. Gong, X.J. Cao, Fluid Phase Equilibr. 284 (2009) 26-30.

[30] S. Marceneiro, P. Coimbra, M.E.M. Braga, A.M.A. Dias, H.C. de Sousa, Fluid Phase Equilibr. 311 (2011) 1-8.

[31] Y.M. Chen, Y.P. Chen, Fluid Phase Equilibr. 282 (2009) 82-87.

[32] A. Tabernero, E.M.M. del Valle, M.A. Galan, J. Chem. Thermodyn. 43 (2011) $711-718$.

[33] S.J. Nejad, H. Abolghasemi, M.A. Moosavian, M.G. Maragheh, Chem. Eng. Res. Des. 88 (2010) 893-898.

[34] C. Garlapati, G. Madras, Fluid Phase Equilibr. 283 (2009) 97-101.

[35] M.H. Hosseini, N. Alizadeh, A.R. Khanchi, J. Supercrit. Fluids 52 (2010) 30-35.

[36] J. Mendez-Santiago, A. Teja, Fluid Phase Equilibr. 158 (1999) 501-510. 